\title{
SHORT- AND LONG-TERM EFFECTS OF USING SHOOTING STRAPS ON FREE THROW ACCURACY OF YOUNG FEMALE BASKETBALL PLAYERS
}

\author{
Miguel-Ángel Gómez ${ }^{1}$, Rasa Kreivyte ${ }^{2}$, and Jaime Sampaio ${ }^{3,4}$ \\ ${ }^{1}$ Faculty of Physical Activity and Sport Sciences, Polytechnic University of Madrid, Spain \\ ${ }^{2}$ Lithuanian Sport University, Department of Coaching Science, Kaunas, Lithuania \\ ${ }^{3}$ Department of Sport Sciences, University of Trás-os-Montes e Alto Douro, Vila Real, Portugal \\ ${ }^{4}$ CreativeLab, Research Center for Sport Sciences, Health and Human Development, Portugal
}

Original scientific paper

UDC: 796.323.2-055.25:796.012.572.4

\begin{abstract}
:
This study identified the short- and long-term effects of using a shooting strap on the accuracy of free throws performed by U15 female basketball players during training and competition. Thirty six female basketball player volunteers (aged 14.3 \pm 0.5 years) from the Lithuanian Schoolchildren Basketball League were randomly assigned to either an experimental or control group. The experimental group used a shooting strap that immobilized movements of the supporting hand while shooting. The control group performed free throws without any training aid. Learning and transfer of performance was assessed before and after the intervention training sessions (4-week intervention program applied 4 times per week), and on a retention test after one year. Results showed that: (a) free throw accuracy was higher after one month and after one year of intervention than before the intervention training program in both practice and competition; (b) the experimental group scored better in practice and competition than the control group after one month and one year of the intervention; and (c) free throw accuracy was higher during training sessions than during competition. The identified short-term and long-term improvements in free throw shooting accuracy support the usage of shooting straps. The use of shooting straps and external assisting devices might allow adjusting programs of training to provide fluent free throw accuracy progress from youth to senior categories.
\end{abstract}

Key words: technique, shooting training, team sports

\section{Introduction}

The process of skill acquisition is one of the major foci of research within the scope of understanding human performance. In basketball, free throw skill and efficiency contributes decisively to the game outcome in men's (Gómez, Lorenzo, Barakat, Ortega, \& Palao, 2008), women's (Gómez, Lorenzo, Sampaio, \& Ibañez, 2006), and youth teams (Lorenzo, Gómez, Ortega, Ibañez, \& Sampaio, 2010). In fact, the free throw accounts for $20 \%$ to $30 \%$ of the points scored during a game (Kozar, Whitfield, Lord, \& Dye, 1994), and is therefore a very important skill to achieve high-level performance.

These unopposed shooting attempts are executed in a standing position from behind the free throw line, with a time limit of five seconds to shoot and with the game clock stopped (Art. 43, FIBA, 2014). Traditionally, free throws have been analyzed using biomechanical and kinematic approaches (Khlifa, Aouadi, Shepard, Chelly, \& Hermassi, 2013; Mullineaux \& Uhl, 2010), variable practice (Memmert, 2006), pre-performance routines (Foster, Weigand, \& Baines, 2006), visual search strategies (Ai-Abood, Bennett, MorenoHernández, Ashford, \& Davids, 2002), or self-regulation behaviors (Cleary, Zimmerman, \& Keating, 2006; Wulf, Raupach, \& Pfeiffer, 2005). Thus, this skill is greatly influenced by both objective factors, such as technique of shooting, training tasks, or skill routines, and subjective factors, such as quality of training methods, physical stability, motivation, or self-confidence (Zuzik, 2011). In fact, even when a player has a good shooting technique, most of the mistakes in free throws may be due to the influence of stress and his/ her lack of control (Feri, Innocenti, \& Pin, 2013). Specifically, in youth-age players we may add certain factors such as the accommodation process to the rule changes (i.e. ball size and weight, or height of the basket) and the character- 
istics of growth that do not satisfactorily match the strength and coordination abilities of players. Thus, the learning of shooting skills should fluently grow with the dynamism of players' characteristics such as age, training experience, and skill execution (Zuzik, 2011).

Free throw effectiveness is related to the developmental age of players. For example, Zuzik (2011) analyzed a sample of U10, U11, U12, U14, U16, U18, and senior age categories of both genders and identified that men steadily increased their accuracy from the U16 age to adult age categories (ranging from $56.9 \%$ to $70.6 \%$, respectively). In contrast, women showed less marked changes from the U10 category to seniors (the values ranged from $45.5 \%$ in U10, $42.9 \%$ in U12 categories, $50.9 \%$ in U11, $52.2 \%$ in $\mathrm{U} 14$, and around $60 \%$ for U16, U18, and senior categories). These findings indicate that the increased experience with age likely play more of a role in players' performance than simply the chronological age of players (Zuzik, 2011). According to these findings, the effective improvement of a not yet automated movement pattern, such as free throws, in these categories depends more on technical than psychological training (Dandy, Brewer, \& Tottman, 2001). However, when the technical execution has been automated, the opposite occurs from that moment onwards - the evolution of performance depends largely on the improvement of shooter's psychological skills (Perreault \& French, 2015).

As Mullineaux and Uhl (2010) have argued, accuracy of free throws is related to consistent and uniform movement patterns that must be trained in youth categories. Thus, the players will likely benefit from an increase in the quantity and quality of free throw-related tasks during training sessions (Zuzik, 2011). However, there is scarce scientific support to describe adequate training programs or training aids that allow this focused improvement, particularly at youth stages (Khlifa, et al., 2013).

In youth category players the skill acquisition of incorrect preparatory movements and actions, as well as concentration on external factors interfere with movement stability and accuracy (Wulf, 2007; Zuzik, 2011). From a coach's perspective, introducing new skills to youth players requires him/her to focus his/her attention on planning and structuring effective learning at the individual level (Chow, Renshaw, Button, Davids, \& Wee Keat, 2014). Thus, when consolidating adequate individual shooting skills, it is recommended to use various non-traditional technical aids (e.g., splints or training balls), and facilities (e.g., reduced hoops or stands for the improvement of shooting trajectory), which can bring benefits to accuracy of the shooting movement pattern and stability of its separate parts (movements) (Wulf, 2007; Zuzik, 2011).

From a technical point of view, the preferred shooting technique is to use a one-handed push or jump shot (Alexander, 2002, 2010; Amberry,
1996). The role of the shooting hand is to provide guidance and force to direct the ball toward the basket. Then, the kinematics of the musculoskeletal systems below the forearm are also of great importance. Not surprisingly, many young female players lack strength to perform the one-handed shot from the free throw line (Alexander, 2010). For these players, free throw shooting requires near to the maximum velocity production. Conversely, the nonshooting hand helps to catch the ball and to stabilize it during the shooting motion. At the point of release, the non-shooting elbow extends and separates the hand completely from the ball to enable the shooting hand to properly direct the ball (Chow, et al., 2014). In fact, during the free throw movement an "off-hand interference" may occur. This issue can be detected in novice, high-school, college and even professional players (Wulf, 2007). Therefore, it is suggested to learn and improve the technique of shooting by one hand from the shoulder with the help of a shooting strap on the non-shooting hand (e.g., holding the ball and shooting with the focus on the non-shooting hand) (Wulf, 2007).

Accordingly, the usage of shooting straps is particularly suggested for the learning and improving the free throw shooting technique (Chow, et al., 2014). The strap corrects the shooting technique (form) by restricting the influence of the nonshooting hand. As a result, the non-shooting hand contributes to the stabilization of the ball before the shot is released; however, the very throw is taken solely by one, the shooting hand. The results obtained for stability and accuracy of free throws with the use of a shooting strap seem positive (Chow, et al., 2014; Zuzik, 2011). This may be due to that competition performance is more affected by the mastery of player's psychological abilities to maintain an optimal level of motivation, selfefficacy and emotional management (i.e., stress management) (Feri, et al., 2013).

In addition, some studies have identified that habits acquired during motor skills learning at youth stages are still present after a specific practice has ceased (Memmert, 2006). Specifically, the use of the shooting strap may create division within common motor program used to shoot jump shots and free throws, when such a division with such a common motor program may be unnecessary and perhaps even undesirable. Basketball players spend a substantial amount of training time improving free throw accuracy; therefore, the use of shooting straps can be a determining factor in improving long-term skill retention (Khlifa, et al., 2013). From a motor learning perspective, the free throw is a closed skill that has very similar constraints when training and competing. Although there can be changes in environmental factors, such as match status or game location, the shooting task is quite consistent and invariant (i.e. distance to the basket, 
time demands, hoop diameter). However, during competition there are other psychological factors influencing the shooting performance (Feri, et al., 2013).

The correct execution of free throws is based on a full body movement that requires high precision. For example, in a ready-to-shoot position, the ball lies on the shooting hand when the player holds it above the forehead and is aiming at the basket (Schmidt, 2012; Schmidt \& Bjork, 1992; Shoenfelt, Snyder, Maue, McDowell, \& Woolard, 2002). The use of shooting straps constraints the motion of the support hand during the release and follow through the shot, and in turn often prompts unwanted compensatory motions down the body's kinematic chain, particularly in the shoulder girdle bilaterally as well as the axial skeleton. With constant practice, the movement becomes automatic. The learning of consistent skills in this way is easily automated and shows short-term and long-term retention after practice has ceased (Button, Macleod, Sanders, \& Coleman, 2003). In particular, the shooting trajectory variability decreases with practice (Zachry, 2005). The research focused on youth male basketball players showed the impact of the ball weight on free throw performance (Arias, 2012). Thus, the use of specific and adjusted techniques are needed for skill acquisition, with a particular focus on the learning process instead on the success or failure of the shot, so that the player will be more mindful and aware of the skill execution (Cleary, et al., 2006).

Research that analyzed the long-term training effects of free throw shooting is scarce. As Memmert (2006) stated, the learning effects should be tested for both short-term and long-term periods to support the importance of motor-learning during the training process of young players in their formative age. However, this approach has not been utilized in research of basketball free throws, especially not the observation of short-term and longterm effects during both practice and competition.

Therefore, the aim of this study was to identify the effect of either using (experimental group) or not using a shooting strap (control group) during practice on accuracy of free throws performed by U15 female basketball players during training sessions and competitions across a complete season. It was hypothesized that short-term (one month) and long-term (one year) effects of shooting strap training would substantially improve accuracy of free throws of young female basketball players both in training and competition.

\section{Methods}

\section{Participants}

Female basketball players ( $\mathrm{N}=36$ ), aged $14.3 \pm 0.5$ years $(m e a n \pm s)$, from a basketball school (Lithuania), voluntarily agreed to participate in this study.
All players competed in the Lithuanian Schoolchildren Basketball League for $4.5 \pm 0.6$ years.

The participants were from two national-level teams and were randomly assigned to a control $(n=18)$ (age: $14.28 \pm 0.46$ years; age at menarche: $13.22 \pm 0.88$ years; body mass: $61.8 \pm 4.2 \mathrm{~kg}$; body height: $170.9 \pm 5.0 \mathrm{~cm})$ or an experimental group $(n=18)$ (age: $14.36 \pm 0.54$ years; age at menarche: $13.06 \pm 0.80$ years; body mass: $63.5 \pm 6.1 \mathrm{~kg}$; body height: $172.4 \pm 6.1 \mathrm{~cm})$.

Both groups were similar in all these characteristics $(\mathrm{p}>05)$ and free throws performance (training $=51.3 \pm 5.1 \%$ and $52.9 \pm 9.0 \%$; competition $=37.2 \pm 5.8 \%$ and $36.6 \pm 7.0 \%$, for the control and experimental group, respectively). Every participant provided a written informed consent in which the procedures were explained and their freedom to withdraw from the study at any was disclosed. Additionally, a written parental informed consent was provided. Both written documents were obtained prior to the study from the participants and their parents. The local Institution Review Board of the Lithuanian Sports University approved this study.

\section{Study design}

The observations of basketball players were made in their natural environment - an indoor facility with the official court. Thus, within- (longterm trends) and between-subject (control and experimental groups) analyses were conducted during the research phases designed to test the influence of shooting straps on youth female basketball players: pre-test, intervention (one month), post-test (after one month), and retention (after one year).

\section{Procedure}

The experimental and control group players attended their practice sessions as usual and participated in the 4-week intervention program applied in 4 sessions per week. For both groups each of free throw workouts consisted of a total of 100 shots (10 sets of 10 shots), all controlled by three expert coaches. Both the made and missed shots were rated according to the following 6-point scale (Zachry, 2005): (a) 5 points - a swish; (b) 4 points - when the basket is made with the ball hitting the front part of the hoop; (c) 3 points - when the basket is made with the ball hitting the right or the left side of the hoop, or after rebounding from the backboard; (d) 2 points - inaccurate shot when the ball rebounds from the front part of the hoop or from the backboard; (e) 1 point - inaccurate shot when the ball rebounds from the right or the left side of the hoop; and (f) 0 points - inaccurate shot when the ball does not even touch the hoop or the backboard. Accordingly, the variable was split into a dichotomous dependent variable: made shots that included the scale values 5, 4 and 3 points, and missed shots that included 2, 1 and 0 points. 
The players in the experimental group used a shooting strap that immobilized the movement of the supporting hand while shooting (if the player was right-handed, the left hand was run into the strap, and if she was left-handed, the same was done with the right hand; see Figure 1). The players in the control group performed the same number of free throws but without any shooting strap (Figure 1). This research design was not cross-sectional due to the long-term retention phase. During four weeks, four times per week, all the players in each practice session performed 100 free throws, recovering the ball after each trial by themselves. This intervention was designed according to Amberry (1996) who suggested that changes in patterns of a shot require a substantial number of free throws (100 free throws per training).

At the beginning of testing, the participants performed running exercises with a ball at low intensity for 10 minutes (warm-up activities). Then they performed 100 free throws (10 sets of 10 shots): after each shot the player ran for the ball herself and then returned to the free throw line. The test was based on the David's Law principle of physiology saying that if you repeat the same motion over and over again, your muscles and coordination ability will physically change to perform that action. Then the player will have his/her muscle memory coordinated to perform free throws with his/her mind clear of pressure and external information (Amberry, 1996). The result of the test was quantified as the number of successful shots expressed as a percentage of all the shots attempted. The exact same procedure was repeated after the intervention training in order to test the short-term effect of a shooting strap (after one month of practice). The retention of the shooting skill was tested one year after the intervention (long-term effect). In the test training sessions the players performed the same routine with warm-up activities and the free throws test (25 minutes). Afterwards, they continued with their training tasks and drills focused on tactical and technical aspects of the game (60 minutes). The tests were supervised by two expert coaches (observers to gather the data) with clear instructions of no interaction between them and the players. Then, the players received the initial information about how to do the tasks (free throws tests), but no feedback or support (i.e., emotional, performancerelated, social) were given during the tests. The coaches' feedback was only given after the training session. Its focus was on the improvement of free throw effectiveness with the emphasis on its importance during games and competitions (performance perspective), but not on the test performance. No emotional information was offered to the player
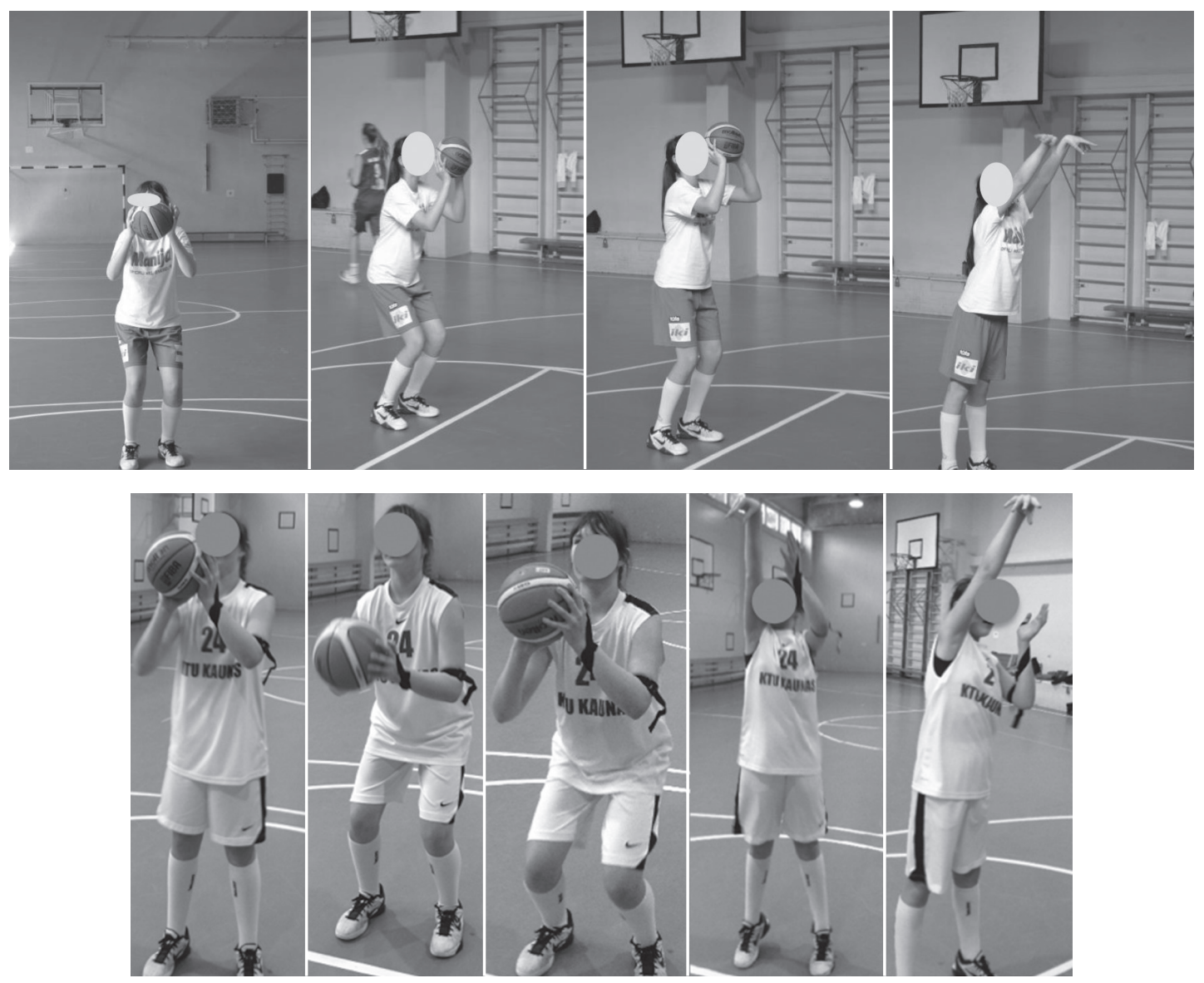

Figure 1. Sequence of photos showing the free throw technique without (upper images) and with the use of shooting straps (lower images). 
about the effectiveness in order not to interfere with the players' performance during the experimental tests.

In order to assess data reliability for each test of 100 free throws an autocorrelation coefficient function was estimated for each test and each player (using lag $=10$ based on trials of 10 free throws). The persistency of free throws accuracy was very high for both the experimental (values of ACF=.89, .90, and .92 for the pre-test, post-test, and retention test, respectively) and control group (values of $\mathrm{ACF}=.88$, .91 , and .93 for the pre-test, post-test, and retention test, respectively).

With the aim to test the effect of the shooting strap on the accuracy of free throws during competition, free throw accuracy was analyzed during the games from the Lithuanian Schoolchildren Basketball League. In total, 13 games were used to calculate average performance profiles in the pre-test $(n=145$ and $n=131$ free throws attempted by the experimental and control group, respectively), posttest ( $\mathrm{n}=155$ and $\mathrm{n}=139$ free throws attempted by the experimental and control group, respectively) and retention phases. In the last phase, the analyzed games belonged to the $2008 / 2009$ season $(n=884$ and $n=869$ free throws attempted by the experimental and control group, respectively).

Free throws, both made and missed, were registered by notational analysis using video footages. Two experienced observers were trained for this task; they were basketball coaches graduated in Sports Sciences, with a minimum of eight years of coaching experience. The weighted Kappa coefficients were used to assess inter-observer and intraobserver reliability (Altman, 1991) during training and competition. The obtained results showed very good mean values for intra-observer (training $\mathrm{k}=.80$; competition $\mathrm{k}=.82$ ), and inter-observer reliability (training $\mathrm{k}=.81$; and competition $\mathrm{k}=.80$ ).

\section{Statistical analysis}

A descriptive statistical analysis was performed using means and standard deviations. The mixed linear model was used to analyse the repeated-measures (i.e. long-term approach) data from players' free throws. The mixed linear model calculated included the following: intervention (pre-test, posttest, and retention test), group (control and experimental), and context (training and competition) as fixed effects and individual players and training sessions as random effects. In order to control for the significant effects of fixed factors, the Bonferroni's post-hoc test was applied to examine the pairwise comparisons of each significant factor; the level of significance was set at $p<.05$. Afterwards, the comparisons among pairs of conditions (i.e. intervention, group and context) were assessed via the standardized mean differences, computed using pooled variance and respective $95 \%$ confidence intervals (Cumming, 2012a; Hopkins, Marshall, Batterham, \& Hanin, 2009). The thresholds for effect size statistics were as follows: $0.2=$ trivial; $0.6=$ small; $1.2=$ moderate; $2.0=$ large; and $>2.0=$ very large (Cumming, 2012b). The statistical analyses were performed using Microsoft Excel spreadsheets (Microsoft, Redmond, WA, USA), Exploratory Software for Confidence Intervals (ESCI) (Cumming, 2012a) and IBM SPSS statistics for windows, Version 21.0 (Armonk, NY, USA: IBM Corp.).

In addition, in order to test the effect of the shooting strap on free throw accuracy the 6-point scale was used for the contexts and between groups, and a repeated measures analysis of variance (ANOVA) was performed. Statistical significance was set at $p<.05$. Effect sizes (ES) were calculated using the partial eta square test and their interpretation was based on the following criteria: $0.01=$ small effect, $0.06=$ medium effect, and 0.14=large effect (Cohen, 1988).

\section{Results}

Table 1 shows free throw accuracy (per-centage values) for both the experimental and control group during training sessions and competitions. Also, the coefficient of variation for each group and context was included. The results showed an improvement of free throw accuracy percentage and a reduction of the $\mathrm{CV} \%$ for the experimental and control group

Table 1. Descriptive statistics (mean, standard deviation, and \% of coefficient of variance) between groups and interventions for free throw accuracy (percentage values)

\begin{tabular}{lccccccccc}
\hline & \multicolumn{3}{c}{ Pre-test } & \multicolumn{3}{c}{ Post-test } & \multicolumn{3}{c}{ Retention } \\
\cline { 2 - 11 } & $\mathrm{M}$ & $\mathrm{SD}$ & $\% \mathrm{CV}$ & $\mathrm{M}$ & $\mathrm{SD}$ & $\% \mathrm{CV}$ & $\mathrm{M}$ & $\mathrm{SD}$ & $\% \mathrm{CV}$ \\
\hline Training & & & & & & & & & \\
Experimental group & 51.28 & 5.05 & 9.8 & 73.72 & 9.05 & 12.3 & 75.17 & 4.89 & 6.5 \\
Control group & 52.94 & 9.03 & 17.1 & 54.89 & 7.85 & 14.3 & 59.44 & 7.37 & 12.4 \\
Competition & & & & & & & & & \\
Experimental group & 37.28 & 5.88 & 15.8 & 55.44 & 6.23 & 11.1 & 67.44 & 6.13 & 8.9 \\
Control group & 36.61 & 7.03 & 19.2 & 38.00 & 5.65 & 14.9 & 44.61 & 5.16 & 11.6 \\
\hline
\end{tabular}


(after one month and one year). These trends were higher for the experimental group.

The results from the mixed linear model (see Table 2) showed that group (control and experimental: $F_{1,204}=178.93 ; \mathrm{p}<.001$ ), intervention (pretest, post-test, and retention test: $F_{2,204}=118.87$; $\mathrm{p}<.001$ ), and context (training and competition: $\left.F_{1,204}=256.69 ; \mathrm{p}<.001\right)$ were statistically significant. Specifically, the pairwise comparisons (Bonferroni post-hoc test) for groups showed that the experimental group achieved higher free throw accuracy than the control group (ES=2.67[2.24-3.11] very large). Also, the comparisons between the intervention periods showed higher values for free throw accuracy on the retention test (a year after the intervention) than on the post-test (one month after the intervention) $(\mathrm{ES}=.37[.29-.45]$ small) or on the pretest $(\mathrm{ES}=0.67[.51-.83]$ small). Besides, free throw accuracy was higher one month after the intervention than pre-intervention ( $\mathrm{ES}=.32[.21-.43]$ small). The context pairwise comparisons showed greater values for free throw accuracy during training sessions than competitions ( $\mathrm{ES}=1.32$ [1.02-1.68] large).

The mixed linear model interactions showed significant results for group $\mathrm{x}$ intervention $\left(F_{2,204}=48.57 ; \mathrm{p}<.001\right)$ and intervention $\mathrm{x}$ context $\left(F_{2,204}=3.93 ; \mathrm{p}<.021\right)$. In order to show the differences between pairwise comparisons for groups and interventions in each context, Figure 2 shows the magnitude of standardized differences (Cohen's d units and 95\% IC). The improvements in the experimental group were very large from the pre-test and were maintained throughout the retention phase. The control group participants showed trivial vari- ation until the post-test but also improved until the retention test.

Table 3 presents the results of main effects and two-way interactions of free throw accuracy by group, intervention, and context for the 6-points scale analysis. There were differences between the three intervention periods and also between the groups. The interactions between factors showed significant effects for intervention and group.

Table 2. Results of mixed linear model for repeated measures of free throw accuracy during training sessions and competitions for the experimental and control groups

\begin{tabular}{lccc}
\hline Main effects and interactions & $\mathrm{df}$ & $\mathrm{F}$ & $\mathrm{p}$ \\
\hline Intercept & 1 & 13789.94 & .001 \\
Intervention (pre-test, post-test & 2 & 118.87 & .001 \\
and retention) & & & \\
Group (experimental and & 1 & 178.93 & .001 \\
control) & & & \\
Context (training and & 1 & 256.70 & .001 \\
competition) & 2 & 48.56 & .001 \\
Intervention $\times$ Group & 2 & 3.93 & .021 \\
Intervention $\times$ Context & 1 & 2.08 & .154 \\
Group $\times$ Context & 2 & 1.749 & .177 \\
\hline Intervention $\times$ Group $\times$ Context & & & \\
\hline
\end{tabular}

Table 3. Results of repeated measures ANOVA for the effects and interactions of free throw performance during training sessions for the experimental and control group

\begin{tabular}{llll}
\hline & $F$ & $p$ & $E S$ \\
\hline Score $(0$ to 5 points $)$ & $24,523.3$ & .001 & .54 \\
Score $\times$ Group & $3,687.6$ & .001 & .48 \\
Score $\times$ Intervention & $4,360.6$ & .001 & .55 \\
\hline
\end{tabular}

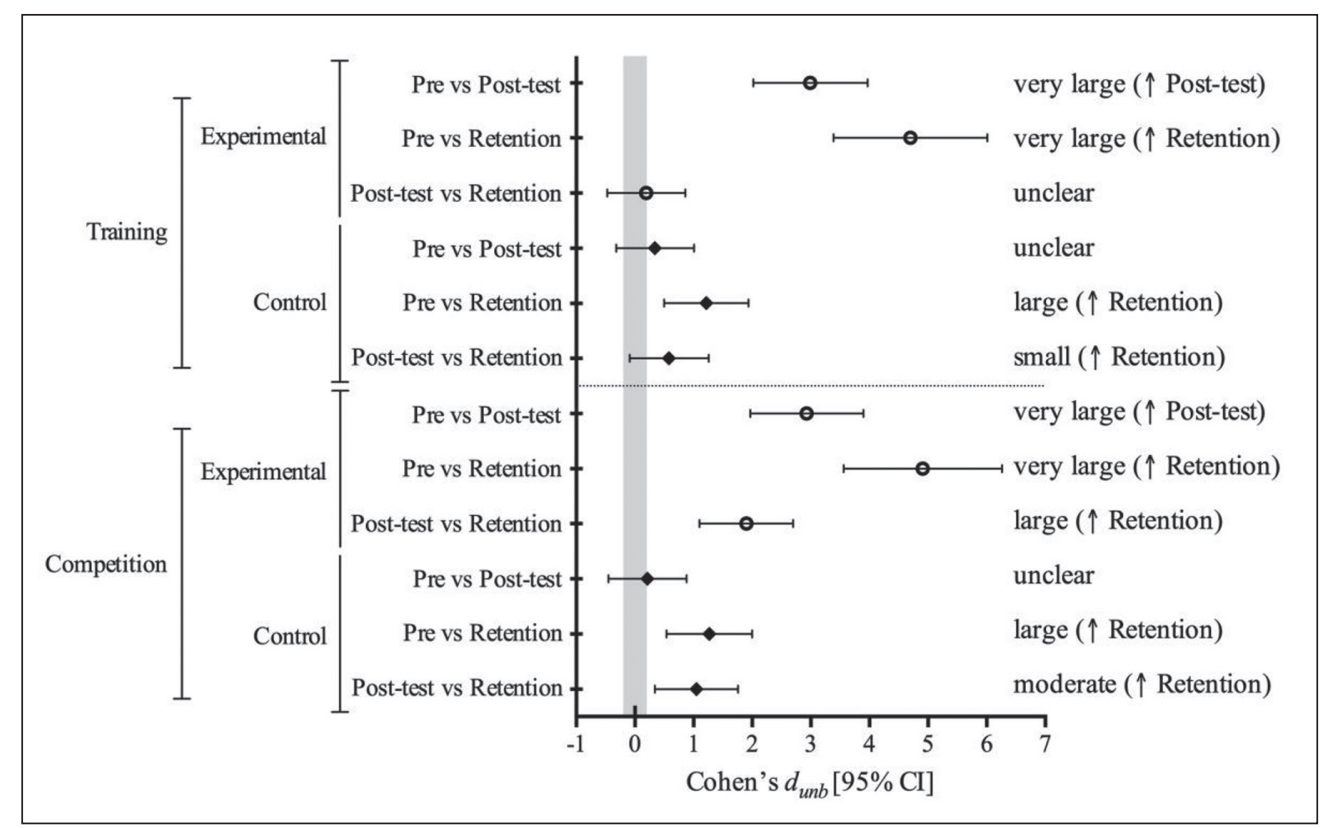

Figure 2. Standardized differences in free throw accuracy between the control and experimental groups during training and competition (Cohen's d values and their $95 \%$ CI). 


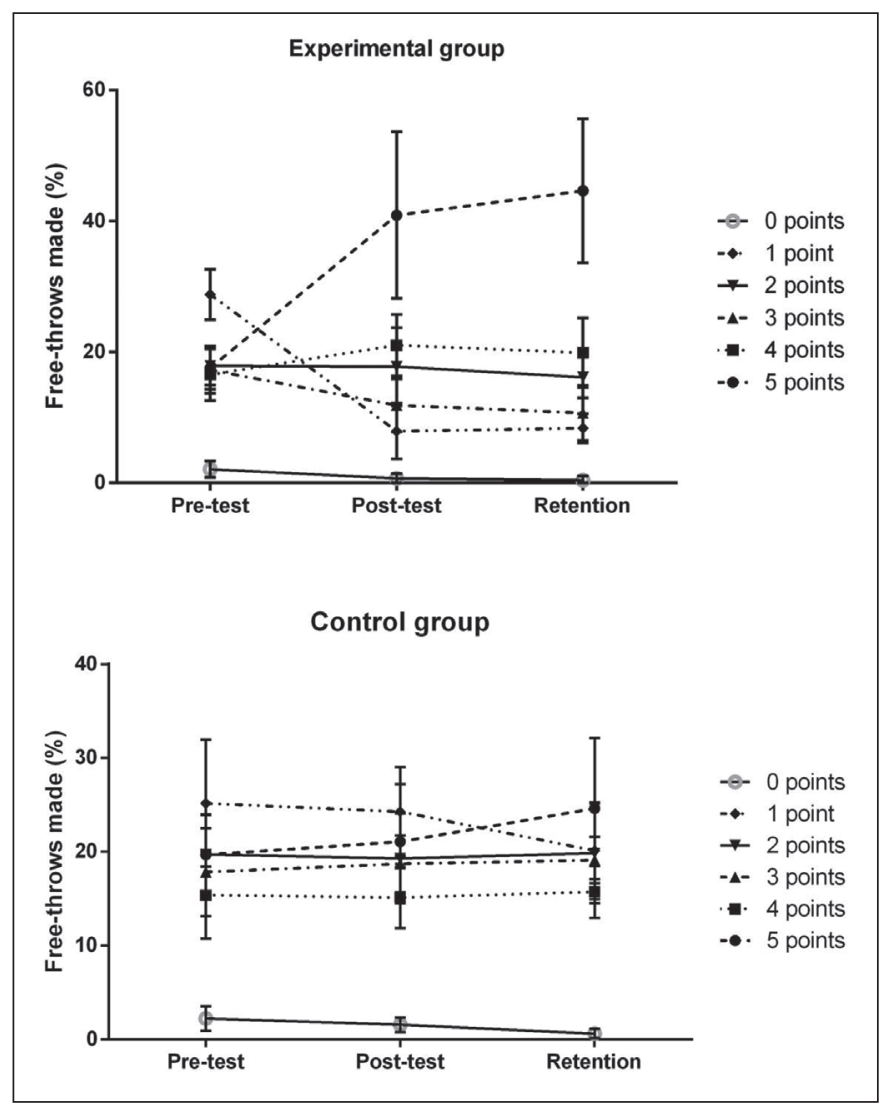

Figure 3. Variations of free throw accuracy according to the scores $(0$ to 5), for the experimental and control group during training sessions.

Figure 3 presents the variation in free throw accuracy according to the scores and intervention $\left(F_{1,35}=4360.6 ; \mathrm{p}<0.001 ; \mathrm{ES}=.75\right)$ for the experimental and control group. The results suggest that subjects from the experimental group improved substantially their free throws scored with 5 points (swishes; when the ball is shot accurately without touching the hoop or the panel).

\section{Discussion and conclusions}

The aim of the study was to identify the short- and long-term effects of using a shooting strap on the accuracy of free throws performed by U15 female basketball players during training sessions and competition. It was hypothesized that there would be both the short-term and long-term improvement in free throw accuracy when training with the shooting strap. The present results support this hypothesis; in fact, the usage of the shooting strap allowed for a substantial improvements in free throw accuracy in the short-term and accuracy level was maintained in the long-term.

Consistency and accuracy are keys for successful free throw shooting in basketball. Highlevel performance appears to be linked with limited variability in kinematic parameters that describe players' shooting technique with the support hand but not in the kinematic chain where greater vari- ability is expected (in the shoulders and axial skeleton) (Khlifa, et al., 2013). The usage of the shooting strap helps to limit this variability in the support hand and could have contributed to the improvements in free throw shooting. In fact, the automaticity and repetitions increase players' muscle memory during free throws (Amberry, 1996). The skill acquisition is individual, complex and dynamic; the task constraints the player needs to solve during practice are carefully manipulated by the coach (i.e., a combination of external assisting devices) in order to increase the optimal coordination for a successful outcome and skill retention (Alexander, 2002).

From a dynamic learning perspective, if the coaches want to improve the skill execution of players, they need to plan tasks that create a supportive learning environment where the players' movement solutions are encouraged, improved and then stabilized (Chow, et al., 2014). However, the stability of dynamic movements need an exposure to key specific constraints such as training aids (i.e., shooting straps) where the acquisition of coordination allows the players to search stable movement patterns during the free throw tasks (Chow, et al., 2014). The aim to modify incorrect free throw skills can be fostered by the manipulation of constraints (i.e., using technical aids) where players can use different movement solutions to improve the skill execution and performance (Button, et al., 2003; Zachry, 2005), as the current results have also shown. Additionally, as was suggested by Arias (2012), the use of technical aids is a requirement needed for the training program adaptation to the youth players' characteristics and needs.

Current results showed that practice sessions with shooting straps significantly improved free throw accuracy by $22 \%$, whereas the control group improved accuracy by $2 \%$. The players' ability to improve free throw accuracy seems related to finetuning adjustments that are identified when shots are missed. The process becomes more important than the outcome. This way, the player tries to search for the stable movement pattern and coordination when using the shooting strap, which imposes optimal positioning and, ultimately, accelerates learning (Alexander, 2010; Cleary, et al., 2006). According to Chow et al. (2014), the day-by-day training sessions set the scene for the next stages of learning. Then, according to the individual strength of cooperative and competitive mechanisms, the player shows non-linear transitions, regressions and progressions. Specifically, the constraints generated by the use of external aids were studied in short- (a training session), mid-term (after one month of practice) and long-term effects (after one year of practice). Conse- 
quently, motor learning and motor development of the free throw skill showed non-linear trends reflecting non-proportionality and multi-stability with variations in the motor patterns maturation. In fact, the variability of both groups during the experimental design showed greater coefficients of variation at the beginning of the experiment $(9.8 \%$ compared with $17.1 \%$ ), but lower differences were evident after one month $(12.3 \%$ compared with $14.3 \%$ ) and greater differences after one year of practice (6.5\% compared with $12.4 \%)$.

The results of the study showed that free throw accuracy was greater during training sessions when compared with competition. After the training period, free throw accuracy during competition improved in the experimental group by $18 \%$; however, these values were significantly lower than those obtained during intervention training. Conversely, free throw accuracy of the control group during the practice sessions and competition did not change significantly. According to Zuzik (2011), free throw accuracy during basketball games is conditioned by the age and also the peculiarity of shooting execution. In a game, the young player (i.e. U15) has to face stressful and pressuring conditions that generate uncomfortable states in him/her, thus lowering free throw accuracy (Zuzik, 2011). This player's decision-making may be due to increasing the level of skill-focused attention to the free throw execution instead of only shooting with one's mind clear of pressure (Liao \& Masters, 2002). The game context may reflect that skill retention and transfer are positively affected during competition, but not at the same level as during training sessions (i.e., no high pressure for the player), probably due to stressful environmental conditions, such as match status, game period, or time remaining. Therefore, it is necessary to adjust training conditions to replicate match scenarios for free throw shooting and in that way improve throw accuracy of youth category players (Zuzik, 2011). In fact, the available research in basketball showed the importance of free throw game-related statistics when analyzing senior female and U16 male basketball categories (Gómez, et al., 2006; 2008; Lorenzo, et al., 2010). Particularly for young female basketball players, it seems extremely important to acquire the correct basketball shooting technique, but also to learn the preroutine techniques that allow improving shooting performance during competition. The available research addresses several different methods of routine movements and actions before a free throw (Chow, et al., 2014). Shooting accuracy is determined by technique, but also by the preparation to perform the movement, for example by paying attention to the sequence of preparatory steps before the free throw execution (Broer \& Zernicke, 1979) and the psychological factors that may affect the movement (Feri, et al., 2013). In fact, the combi- nation of pre-routines, attention and movements should be carefully prepared to maximize free throw accuracy (Ai-Abood, et al., 2002; Amberry, 1996). It is recommended for both young and skilled basketball players to focus their attention in all these combinations with teaching aids when shooting free throws. Thus, players should focus their attention on external factors when executing free throws (the front part of the basketball hoop). The present results seem also to reinforce this statement, because participants from the experimental group showed a greater percentage of free throws made after one month and one year than the control group $(73.7 \%$ and $75.2 \%$ compared with $54.9 \%$ and $59.4 \%$, respectively). It was also suggested that shooting straps can help to adjust the position of the shooting hand and fingers during shooting (Palubinskas, 2004) and, therefore, can lead to an efficient execution and consolidate the steady movements of hand and fingers when releasing the ball. Conversely, the control group had more missed shots $(45.1 \%$ and $40.6 \%$ after one month and one year, respectively), that is, short and long misses that can be caused by the process of accomodation the motor development (i.e., body growth) and motor control (i.e., deficits in strength and power) during adolescence (Zuzik, 2011). Players try to adapt their shooting execution, but they may reflect a break in the movement rhythm, or poor arc trajectory (Khlifa, et al., 2013; Mullineaux \& Uhl, 2010; Schmidt \& Bjork, 1992). Researchers and specialists of shooting agree that players' left or right missed shots are mostly caused by technical errors in shooting (Amberry, 1996; Broer \& Zernicke, 1979; Lidor, 2007; Wissel, 2004; Zachry, 2005).

The present study has limited impact in other basketball contexts. In fact, the present research is focused on young female players during one complete season (one year), but the factors related to the improvements of experimental group can also be related to other factors not accounted for in the study, such as psychological factors that may modify the free throw performance during competitions or the total amount of practice accumulated by the players. Both aspects should be controlled in further research, as was suggested in recent studies (Feri, et al., 2015; Perreault \& French, 2013). In addition, the gender or the formative long-term perspective (e.g., study from U12 to U18 categories) could increase the information about how to improve the free throw performance from a multidimensional perspective.

The main conclusions of the study showed that: (i) free throw accuracy was higher after one month of intervention and after one year than before the training program in both training sessions and competition; (ii) the experimental group scored better than the control group after one month of intervention and after one year in training sessions 
and competition; and (iii) free throw accuracy was higher during training sessions than during competition.

\section{Practical applications}

The current study underlined that using shooting straps might reduce variability, likely only in the upper extremity (the non-shooting hand), thus improving free throw accuracy. This study represents a first step to promote further studies specially focused on the shooting / nonshooting hand execution during youth basketball games, not only considering free throws, but also the shooting execution during live-play actions. In particular, this rationale should be related to anecdotal evidences that suggest that the strap can negatively affect the inter-limb coordination ability of the whole body (Cortis, et al., 2011). Additionally, it seems reasonable to consider that players could learn how to manage stress derived from competition if they are usually training in similar conditions. That is the reason why coaches should use stress inoculation training as the fundamental way to improve players' psychological skills and get them progressively used to a high level of anxiety. To do so, training tasks should involve incentive systems to get the goal and reinforcement when getting it. The present task design of shooting ten sets of ten repetitions (100 shots) could be adequate to improve the technique but not the psychological skills needed in competition. In order to do so, when the training tasks involve a competition routine (e.g. every shot made add one point but a miss rest one point), the psychological demands come closer to those of the competition.

\section{References}

Ai-Abood, S., Bennett, S.J., Moreno-Hernández, F., Ashford, D., \& Davids, K. (2002). Effect of verbal instructions and image size on visual search strategies in basketball free-throw shooting. Journal of Sports Sciences, 20, $271-278$.

Alexander, M.J. (2002). Mechanics of the basketball free throw. Winnipeg: University of Manitoba.

Alexander, M.J. (2010). The effectiveness of the Shot Loc training tool on basketball free throw performance and technique. A biomechanical analysis. Winnipeg: University of Manitoba.

Altman, D.G. (1991). Some common problems in medical research. In D.G. Altman (Ed.), Practical statistics for medical research (pp. 403-409). London: Chapman \& Hall.

Amberry, T. (1996). Free throw: 7 steps to success at the free throw line. New York: Harper Collins.

Arias, J.L. (2012). Influence of ball weight on shot accuracy and efficacy among 9-11 year-old basketball male players. Kinesiology, 44(1), 52-59.

Broer, M.R., \& Zernicke, R.F. (1979). Efficiency of human movement (4 ${ }^{\text {th }}$ ed.). Philadelphia, PA: W.B. Saunders.

Button, C., Macleod, M., Sanders, R., \& Coleman, S. (2003). Examining movement variability in the basketball freethrow action at different skill levels. Research Quarterly for Exercise and Sport, 74, 257-269.

Chow, J.Y., Renshaw, I., Button, C., Davids, K., \& Wee Keat, C.T. (2014). Effective learning design for the individual. In A. Ovens, T. Hopper \& J. Butler (Eds.), Complexity thinking in physical education (pp. 121-134). London: Routledge.

Cleary, T.J., Zimmerman, B.J., \& Keating, T. (2006). Training physical education students to self-regulate during basketball free throw practice. Research Quarterly for Exercise and Sport, 77, 251-262.

Cohen, J. (1988). Statistical power analysis for the behavioral sciences $\left(2^{\text {nd }}\right.$ ed.). New York: Academic Press.

Cortis, C., Tessitore, A., Lupo, C., Pesce, C., Fossile, E., Figura, F., \& Capranica, L. (2011). Inter-limb coordination, strength, jump, and sprint performances following a youth men's basketball game. Journal of Strength and Conditioning Research, 25(1), 135-142.

Cumming, G. (2012a). ESCI-The New Statistics: Estimation for better research. Retrieved February 14, 2014, from: www.latrobe.edu.au/psy/research/cognitive-and-developmental-psychology/esci

Cumming, G. (2012b). Understanding the new statistics: Effect sizes, confidence intervals, and meta-analysis. London: Routledge.

Dandy, J., Brewer, N., \& Tottman, R. (2001). Self-consciousness and performance decrements within a sporting context. Journal of Social Psychology, 141(1), 150-152.

Feri, F., Innocenti, A., \& Pin, P. (2013). Is there psychological pressure in competitive environments? Journal of Economic Psychology, 39, 249-256.

Fédération Internationale de Basketball Amateur (FIBA). (2014). 2014 Official Basketball Rules. Barcelona: FIBA Central Board.

Foster, D.J., Weigand, D.A., \& Baines, D. (2006). The effect of removing superstitious behavior and introducing a pre-performance routine on basketball free-throw performance. Journal of Applied Sport Psychology, 18, 167-171. 
Gómez, M.A., Lorenzo, A., Barakat, R., Ortega, E., \& Palao, J.M. (2008). Differences in game-related statistics of basketball performance by game location for men's winning and losing teams. Perceptual and Motor Skills, 106(1), 43-50.

Gómez, M.A., Lorenzo, A., Sampaio, J., \& Ibáñez, S.J. (2006). Differences in game-related statistics between winning and losing teams in women's basketball. Journal of Human Movement Studies, 51, 357-369.

Hopkins, W.G., Marshall, S.W., Batterham, A.M., \& Hanin, J. (2009). Progressive statistics for studies in sports medicine and exercise science. Medicine and Science in Sports and Exercise, 41(1), 3-12.

Khlifa, R., Aouadi, R., Shepard, R., Chelly, M.S., \& Hermassi, S. (2013). Effect of a shoot training programme with a reduced hoop diameter rim on free-throw performance and kinematics in young basketball players. Journal of Sport Sciences, 31, 497-504.

Kozar, B., Whitfield, K.E., Lord, R.H., \& Dye, B. (1994). Importance of free-throw at various stages of basketball games. Perceptual and Motor Skills, 78, 243-248.

Liao, C.M., \& Masters, R.S. (2002). Under psychological stress. Journal of Sport and Exercise Psychology, 24(2), 289-305.

Lidor, R. (2007). Preparatory routines in self-paced events: Do they benefit the skilled athletes? Can they help the beginners? In G. Tenenbaum \& R.C. Eklund (Eds.), Handbook of sport psychology (3 ${ }^{\text {rd }}$ ed.) (pp. 445-465). Hoboken, NJ: John Wiley and Sons.

Lorenzo, A., Gómez, M.A., Ortega, E., Ibáñez, S.J., \& Sampaio, J. (2010). Game related statistics which discriminate between winning and losing under-16 male basketball games. Journal of Sports Science and Medicine, 9(4), 664.

Memmert, D. (2006). Long-term effects of type of practice on the learning and transfer of a complex motor skill. Perceptual and Motor Skills, 103, 912-916.

Mullineaux, D.R., \& Uhl, T.L. (2010). Coordination-variability and kinematics of misses versus swishes of basketball free throws. Journal of Sports Sciences, 28, 1017-1024.

Palubinskas, E. (2004). The jump shot. FIBA Assist Magazine, 7, 6-11.

Perreault, M.E., \& French, K.E. (2015). External-focus feedback benefits free-throw learning in children. Research Quarterly for Exercise and Sport, 86(4), 422-427.

Schmidt, A. (2012). Movement pattern recognition in basketball free-throw shooting. Human Movement Science, 31(2), 360-382.

Schmidt, R.A., \& Bjork, R.A. (1992). New conceptualizations of practice: Common principles in three paradigms suggest new concepts for training. Psychological Science, 3(4), 207-217.

Shoenfelt, E.L., Snyder, L.A., Maue, A.E., McDowell, C.P., \& Woolard, C.D. (2002). Comparison of constant and variable practice conditions on free-throw shooting. Perceptual and Motor Skills, 94(3), 1113-1123.

Wissel, H. (2004). Basketball - Steps to success. Champaign, IL: Human Kinetics.

Wulf, G. (2007). Attention and motor skill learning. Champaign, IL: Human Kinetics.

Wulf, G., Raupach, M., \& Pfeiffer, F. (2005). Self-controlled observational practice enhances learning. Research Quarterly for Exercise and Sport, 76, 107-111.

Zachry, T. (2005). Effects of attentional focus on kinematics and muscle activation patterns as a function of expertise. Las Vegas, NV: University of Nevada.

Zuzik, P. (2011). Free throw shooting effectiveness in basketball matches of men and women. Sport Science Review, 20, 149-160.

Submitted: April 15, 2016

Accepted: February 10, 2017

Correspondence to:

Miguel Ángel Gómez Ruano

Faculty of Physical Activity and Sport Sciences

Polytechnic University of Madrid

C/ Martín Fierro s/n; 28040, Madrid, Spain

E-mail: miguelangel.gomez.ruano@upm.es 